\title{
Action verbal fluency in Parkinson's patients
}

\author{
Fluência verbal de ação em pacientes com doença de Parkinson \\ Inês Tello Rodrigues', Joaquim J. Ferreira², Miguel Coelho², Mario M. Rosa², Alexandre Castro-Caldas
}

\begin{abstract}
We compared the performance of 31 non-demented Parkinson's disease (PD) patients to 61 healthy controls in an action verbal fluency task. Semantic and phonemic fluencies, cognitive impairment and behavioural dysfunction were also assessed. The mean disease duration of PD was 9.8 years (standard deviation $(S D)=6.13)$. There were no age $(U=899.5, p=0.616)$, gender(chi-square $=0.00, p=1.00)$ or literacy $(U=956, p=0.96)$ differences between the two groups. A significant difference was observed between the two groups in the action verbal fluency task $(U=406.5, p<0.01)$ that was not found in the other fluency tasks. The education level was the only biographical variable that influenced the action (verb) fluency outcomes, irrespective of disease duration. Our findings suggest a correlation between the disease mechanisms in PD and a specific verb deficit, support the validity of the action (verb) fluency as an executive function measure and suggest that this task provides unique information not captured with traditional executive function tasks.
\end{abstract}

Keywords: Parkinson's disease, language, verbal fluency tests, action verbal fluency test.

\section{RESUMO}

Este estudo comparou o desempenho em provas de fluência verbal semântica, fonêmica e de ação, em 31 pacientes com doença de Parkinson (DP), sem demência, e 61 controlos saudáveis. As funções executivas e comportamentais foram igualmente avaliadas. 0 tempo de evolução foi de 9,8 anos ( $D P=6,13)$. Não foram encontradas diferenças de idade $(U=899,5, p=0,616)$, género $\left(X^{2}=0,00, p=1,00\right)$ ou literacia $(U=956, p=0,96)$ entre os dois grupos. Diferenças significativas foram encontradas na prova de fluência verbal de ação $(U=406,5$, $p<0,01)$ que não se verificaram nas restantes provas. 0 nível educacional foi a única variável biográfica que influenciou o desempenho das tarefas, independentemente do tempo de evolução da doença. Os resultados sugerem uma correlação entre os mecanismos patológicos da DP e um déficit específico para a evocação de verbos e que a prova de fluência de ação providencia uma informação importante que não é detectada pelos restantes testes executivos.

Palavras-chave: doença de Parkinson, linguagem, fluência verbal, fluência verbal de ação.

Grammatical categories, such as verbs and nouns, are the basic linguistic elements in all human languages. The representation of these two categories in the brain remains a controversial issue in terms of both neuropsychological and imaging evidence.

Several classic studies in patients who have suffered brain damage suggest that the knowledge of names or verbs can be spared or damaged following a neurological lesion. The hypothesis that the distinction between nouns and verbs at different levels of representation might take place in different cortical areas, however, poses a problem to researchers when attempting to identify neuronal areas or circuits involved in the processing of the different categories. Vigliocco's review ${ }^{1}$ suggests that a neural dissociation is observed between the processing of object words (nouns) and action words (typically verbs).
The action verbal fluency test was developed by Piatt et al. ${ }^{2}$ based on findings indicating that verb production is primarily associated with left fronto-striatal circuits (together with the posterior temporal region and underlying white matter), whereas the production of nouns is primarily mediated by the temporo-parietal areas of the hemisphere dominant for language ${ }^{3,4}$. The fronto-striatal circuits are neuronal pathways that create a functional association between the basal ganglia, caudate nucleus, putamen, globus pallidus and frontal lobe functions and are involved in motor disorders such as Parkinson's disease (PD).

As previously shown, data from Parkinson's patients ${ }^{5}$, HIV-1 patients $^{6}$ and normative groups $s^{7,8}$ support the validity of action fluency as an indicator in the assessment of frontal systems.

In this study, we analysed a possible influence of a more frontal implication in linguistic production in PD patients

\footnotetext{
${ }^{1}$ Universidade Católica de Portugal, Instituto de Ciências da Saúde, Centro Interdisciplinar de Investigação na Saúde, Lisboa, Portugal;

${ }^{2}$ Universidade de Lisboa, Faculdade de Medicina, Instituto de Medicina Molecular, Lisboa, Portugal.

Correspondence: Inês T. Rodrigues; Palma de Cima, 1649-023 Lisboa; E-mail: saude@ics.lisboa.ucp.pt

Conflict of interest: There is no conflict of interest to declare.

Received 18 January 2015; Received in final form 05 February 2015; Accepted 25 February 2015.
} 
without dementia and explored the action fluency test as a supplementary instrument for assessing the integrity of frontal-subcortical circuits when compared to traditional fluency tests.

\section{METHOD}

\section{Participants}

The study sample was comprised of 31 PD patients without dementia and 61 healthy controls matched for age, years of education, gender and residence area. Parkinson's disease was diagnosed according to the United Kingdom Parkinson's Disease Society brain bank diagnostic criteria for idiopathic PD. None of the patients had a history of neurological or psychiatric disease other than PD. Patients with signs suggesting atypical Parkinsonian syndrome were also excluded.

All PD patients were taking anti-Parkinsonian medication regularly at the time of the evaluations. The native language of all participants was Portuguese.

\section{Assessments}

Behavioural abnormalities were evaluated using the Frontal Behavioural Inventory (FBI). Cognitive impairment was screened using the Mini-Mental State Examination (MMSE) with a supplementary clinical judgment of an assisting physician. Evaluation of depression was performed using the Portuguese Version from the Center for Epidemiologic Studies Depression Scale (CES-D). According to Schrag et al. ${ }^{9}$, the CES-D is acceptable for use in PD in terms of language and format. Because the CES-D contains few somatic items and no items regarding loss of interest, it is unlikely to be significantly contaminated by the non-depressive symptoms of PD and may be useful across the range of PD disease severity. Potential study participants were excluded if they reported any incapacity to understand the experimental design, major depression or any neurological illness other than PD. None of the patients present agrammatical speech that was evaluated by a speech therapist with an analysis from spontaneous discourse and the Cookie thief description from the Boston Diagnostic Aphasia Examination (BDAE). All study participants provided informed, written consent, and the institution's ethics committee approved the study protocol.

\section{Procedures}

Participants were tested individually in a quiet room by the same examiner. Those with motor fluctuations were tested when they were in the on stage.

All participants were administered standardised tests of letter (P, M, R), semantic fluency (animal, fruits and supermarket goods) and action verbal fluency ${ }^{1}$. Examiner instructions for the action fluency test were adapted from the original author" ${ }^{1,5}$ as follows: "I would like you to tell me as many different things as you can think of that people do. I do not want you to use the same word with different endings, like eat, eating, and eaten. Just give me single words such as eat, rather than a sentence or phrase. Can you give me an example of something that people do?"If the response was unacceptable, participants were asked to provide another example. If the response was adequate, the examiner answered: "That's the idea. Now you have one minute to tell me as many different things as you remember of things that people do".

The primary outcome was the total numbers of unique verbs generated in 60 seconds in the action verbal fluency test. The secondary variables were the total number of items in traditional fluency tests and the influence of demographic variables.

The letter and semantic fluency exams were administered in the standard manner. Letter fluency consisted of three separate 60-second rounds in which participants were asked to name as many words as possible beginning with the letters P, M and R. The choice of these letters, instead of the usual F, A and S was based both on: a) their orthographic transparency, and b) the number of words in the lexicon (entries in a Portuguese dictionary) beginning with these letters. According to this, $\mathrm{P}$ is the easiest and $\mathrm{R}$ the most difficult letter in the $\operatorname{task}^{10}$.

For semantic fluency, the participants were instructed to generate the names of as many animals, fruits and supermarket goods as possible. The score obtained in the fluency tasks corresponds to the total number of words correctly produced. For both semantic and letter fluency exams, participants were asked to refrain from responding with proper names, repeated words or words previously mentioned with a different suffix. The order of administration of the tasks was randomised across participants to avoid any priming influence.

A total of 37 patients and 63 controls were included. Six patients were excluded from the analysis because they did not fulfil the inclusion criteria [depression $(n=3)$ and illiteracy $(n=3)]$. Two controls were also excluded due to depression.

The mean disease duration of PD was 9.8 years $(\mathrm{SD}=6.13)$. There were no age $(\mathrm{U}=899.5, \mathrm{p}=0.616)$, gender (chi-square $=0.00, p=1.00)$ or literacy $(U=956, p=0.96)$ differences between the two groups (Table 1).

\section{Statistical analysis}

The total performance in the verbal fluency tests was compared between the two groups. The various demographic variables were analysed to determine whether or not they significantly influence the total test scores. To compare the performance of the two groups in each of the tests, a MannWhitney test was used because there was not a normal distribution among all the variables. Thus, it was not possible to employ a Student's t-test for independent samples.

SPSS (Statistical Package for the Social Sciences - version 19.0) was used for the statistical analysis of the data. 


\section{RESULTS}

The action verbal fluency task was the only fluency task that showed statistically significant differences between the groups $(\mathrm{U}=406.5, \mathrm{p}=0.00)$ (Table 2, Figure).

The analysis did not detect any significant influence of age on the different task scores. Although no significant impact of age was observed, the results obtained from the Spearman correlation showed a non-significant trend for the performance to decrease as age increases. The Spearman's

Table 1. Clinical and demographic characteristics of patients and controls.

\begin{tabular}{|c|c|c|c|c|}
\hline & $\mathrm{N}$ & $\mathrm{M} \pm \mathrm{SD}$ & Min & Max \\
\hline \multicolumn{5}{|l|}{ Patients gender } \\
\hline Female & 17 & & & \\
\hline Male & 14 & & & \\
\hline \multicolumn{5}{|l|}{ Age } \\
\hline [50-60] & 8 & & & \\
\hline$[61-70]$ & 11 & $67.3 \pm 8.06$ & 50 & 80 \\
\hline$>70$ & 12 & & & \\
\hline \multicolumn{5}{|l|}{ Years of education } \\
\hline 4 & 11 & & & \\
\hline$[4-9]$ & 9 & $8.5 \pm 4.03$ & 4 & 16 \\
\hline ]9-12] & 5 & & & \\
\hline$>12$ & 6 & & & \\
\hline \multicolumn{5}{|c|}{ Time of disease (years) } \\
\hline 3 & 3 & & & \\
\hline$[4-7]$ & 12 & & & \\
\hline$[8-15]$ & 10 & $9.8 \pm 6.13$ & 3 & 21 \\
\hline$>15$ & 6 & & & \\
\hline Controls gender & 34 & & & \\
\hline Female & 28 & & & \\
\hline Male & 16 & & & \\
\hline Age & 21 & & & \\
\hline [50-60] & 25 & & & \\
\hline [61-70] & 22 & & & \\
\hline$>70$ & 18 & & & \\
\hline Years of education & 10 & $66.5 \pm 8.03$ & 52 & 83 \\
\hline 4 & 12 & & & \\
\hline \multicolumn{5}{|l|}{$[4-9]$} \\
\hline \multicolumn{5}{|l|}{ ]9-12] } \\
\hline$>12$ & & $8.4 \pm 4.0$ & 4 & 16 \\
\hline
\end{tabular}

correlation coefficient measures the intensity of the relationship between two ordinal variables. By contrast, academic education was significantly related to an increase of the total number of produced items $(\mathrm{p}=0.036)$. No effect of gender was observed on the performance of any of the tests $(p=0.811)$. A correlation analysis performed to check for an eventual influence of the disease progression on the action verbal fluency test revealed no significant correlation between these two variables $(\mathrm{p}=0.886)$.

\section{DISCUSSION}

We found a significant difference between patients with Parkinson's disease and a matched control group that performed better in the action verbal fluency task. This difference was not replicated with the other fluency tasks.

The study from Péran et al. ${ }^{11}$ gives evidence that nondemented PD patients may present a particular difficulty to produce verbs in a word generation situation. Other studies $^{12,13}$ suggest that the processing of verbs is supported by the frontal lobes, requiring a complex network of syntactical and grammatical information coordinated by an executive

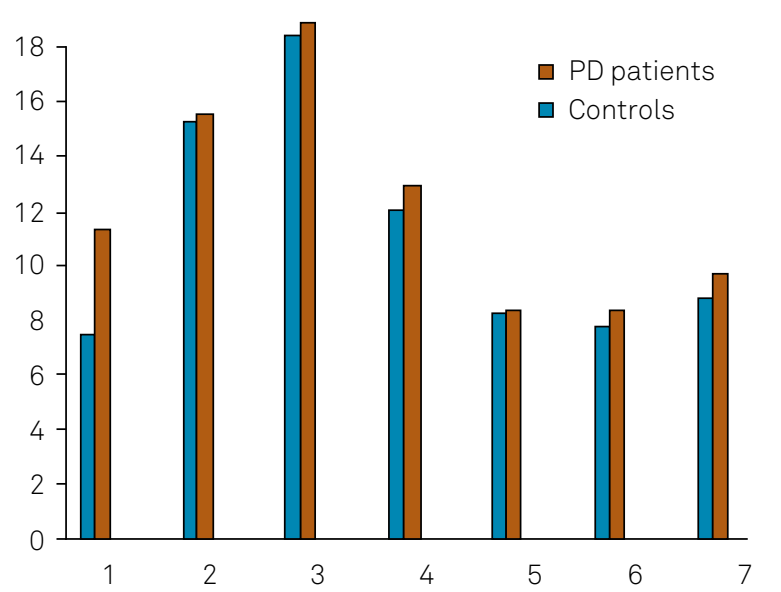

1: Action verbal fluency task; 2: Semantic fluency (animals); 3: Semantic fluency (supermarket goods); 4: Semantic fluency (fruits); 5: Phonemic fluency (M); 6: Phonemic fluency (R); 7: Phonemic fluency (P). PD: Parkinson's disease.

Figure 1. Results from the different fluency tasks in the groups.

Table 2. Means from the different verbal fluency tasks and the results from the Mann-Whitney test for the two groups.

\begin{tabular}{|c|c|c|c|c|c|c|c|c|}
\hline & \multicolumn{3}{|c|}{ Patients } & \multicolumn{3}{|c|}{ Control Group } & \multirow[b]{2}{*}{ U } & \multirow[b]{2}{*}{$p$} \\
\hline & $M \pm s d$ & $\min$ & $\max$ & $M \pm S D$ & $\min$ & $\max$ & & \\
\hline Action F & $7.5 \pm 3.11$ & 3 & 15 & $11.4 \pm 3.62$ & 6 & 19 & 406.5 & 0.00 \\
\hline Animals & $15.3 \pm 3.96$ & 7 & 24 & $15.5 \pm 3.35$ & 8 & 24 & 925.5 & 0.71 \\
\hline Supermarket & $18.6 \pm 3.75$ & 12 & 26 & $19.4 \pm 3.69$ & 10 & 27 & 821.0 & 0.22 \\
\hline Fruits & $13.1 \pm 2.34$ & 9 & 19 & $12.9 \pm 2.35$ & 7 & 18 & 938.0 & 0.89 \\
\hline M & $8.3 \pm 3.86$ & 3 & 19 & $8.4 \pm 3.27$ & 3 & 17 & 905.5 & 0.69 \\
\hline $\mathrm{R}$ & $7.9 \pm 3.45$ & 1 & 17 & $8.4 \pm 2.55$ & 3 & 15 & 810.5 & 0.26 \\
\hline$P$ & $8.9 \pm 3.70$ & 1 & 18 & $9.8 \pm 2.60$ & 4 & 15 & 760.5 & 0.10 \\
\hline
\end{tabular}

M: mean; SD: standard deviation. 
system. These hypotheses are supported by studies conducted in healthy subjects who showed a selective activation of the left inferior frontal gyrus, during verb production ${ }^{14}$ and an activation of the low frontal cortex in tasks requiring syntactical and morphological processing ${ }^{15}$. Cappelletti et al. ${ }^{16}$ reinforced the idea that the medial anterior portion of the left frontal cortex is critical for verb processing.

In the present study, several verbal fluency tests were analysed in $31 \mathrm{PD}$ patients without dementia. Our purpose was to compare the performance of PD patients with that of a control group and verify whether or not there were differences in the performance of the different tests.

The results of any verbal fluency test are closely related to the integrity of executive functions ${ }^{17}$. However, they depend on several factors and are thus not considered pure tasks from the point of view of the assessed functions. A synchronised involvement of different cognitive mechanisms is highlighted by several studies ${ }^{18}$. In regards to the relationship between verbal fluency tests and the assessment of language and executive functions, evidence has shown that verbal fluency tasks partially depend on a linguistic component ${ }^{19}$, the executive aspects of language processing, specifically the construction of concepts ${ }^{20}$, and the strategies for lexical search used throughout the test ${ }^{21}$.

In this context, other studies ${ }^{5}$ suggest that the action verbal fluency test can be useful as an additional measure of executive functions and as a more sensitive indicator of the integrity of the frontal-subcortical circuit than the traditional semantic or phonemic fluency tests. This is due to the assumption that verb production is primarily associated with left fronto-striatal circuits ${ }^{3}$. The results of the action fluency test are consistent with this principle, for they have demonstrated higher sensitivity to the physiopathology of frontostriatal circuits than phonemic or semantic fluency tasks ${ }^{2}$. Several studies conducted with both clinical samples and individuals without pathology have supported the validity of action fluency as an indicator of executive functions ${ }^{6,16}$.

In this line of thought, the action verbal fluency test can simply represent an assessment indicator of some frontal functions, with higher sensitivity and specificity than traditional verbal fluency tests. Some arguments support this possibility: On one hand, the phonemic fluency test, described as the most accurate in frontal lesions, is not always reliable ${ }^{22}$, and the participants can become familiarised with the processes involved in the execution of this test. On the other hand, poor performance in the semantic fluency test is commonly associated with parieto-temporal lesions, and thus this test is not sensitive to frontal changes. The fact that the PD patients studied here present action fluency values much lower than controls and that such a difference was not visible in phonemic fluency corroborates this idea. Thus, the action verbal fluency test may be a useful instrument to complement those existing in clinical practice and in scientific research to assess executive functions.
Considering that this study identified a specific deficit in verb production in PD patients, it would be interesting to confirm these results with another instrument. Because the naming of action images is described by several studies to be limiting and restrictive in the generalisation of results ${ }^{23}$, an alternative would be the presentation of video stimuli, such as that presented in the study by d'Honincthun and Pillon ${ }^{24}$. The replication of our results using a different test will contribute to validating the action fluency test as an instrument for verb evocation assessment in clinical practice as well as in research.

The development and validation of new indicators of frontal functions are important, as traditional neuropsychological assessment tests in this domain are frequently not specific enough. It is therefore important to have a neuropsychological assessment instrument to assess the evocation of verbs that is sensitive to a specific deficit and that allows the determination of some of its contours.

The results of the action fluency test were significantly lower in the clinical group compared to the control group. One of the explanations for this effect could be related to the hypothesis that the action fluency test is intrinsically more challenging and likely requires the use of a considerable neuronal network. While semantic or phonemic fluency tasks are facilitated by semantic or phonologic contexts provided by the examiner, action verbal fluency requires the restoration of an entire lexical class (verbs). As the instructions provided to the participant involved "things that people can do", however, the individuals tended to provide answers related to aspects of daily life, even describing activities of daily living. This fact suggests the hypothesis that, despite being a general instruction, the subjects make use of a long-term memory and tend to contextualise the answer and organise it much more coherently than in the phonemic verbal fluency test. The fact that, in the control group, the average number of produced verbs in the action fluency test was higher than in the phonemic fluency test supports this reasoning. On the other hand, because verbal fluency tests require strategies involving lexical searching and fast articulatory production, it is vital to distinguish articulation deficits from linguistic deficits in PD patients. The absence of statistically significant differences between the performance of patients and controls in traditional verbal fluency tests seems to exclude the influence of a global difficulty in word production, which is consistent with previous reports ${ }^{25}$. The fact that the performance of the clinical group was slightly lower than that of control groups in all tests can be explained by the bradykinesia that is characteristic of PD. However, this does not clarify the significant difference found in the action fluency test. Thus, it was necessary to establish a satisfactory justification for the disparity in the production of the different grammatical categories.

It is possible that the deficit in verb generation found in PD patients may correspond to a disturbance in the ability 
to access both brain representations of actions and their linguistic forms due to the frontal dysfunction shown by these patients. In support of this hypothesis, Boulenger et al. ${ }^{26}$ provided evidence for a shared cognitive and neuronal substrate of actions and action semantics related to words.

Conversely, the specific deficit for verbs can reflect a dysfunction of the executive system that relies on the fronto-striatal system, affecting the ability to coordinate and manipulate the wide range of information that is associated with a verb. This deficit may be interpreted as an early and possibly isolated effect of the alteration of executive functions associated with the physiopathology of fronto-striatal circuits.

Concerning the effect of biographical variables, the results of the present study are in line with the existing literature, as they indicate that the generating of words, and more specifically of verbs, is significantly influenced by academic education. This is not surprising given the vast literature reporting the role of academic education in verbal abilities ${ }^{27}$. The years of disease duration did not correlate with the performance of the clinical group in the different tests. One could expect that, as the disease progresses, its effects would become visible in the final score of the tests. One interpretation for the lack of this correlation could be that the inclusion criteria enabled the small clinical sample to be more homogeneous. However, it is important to note, that in the study conducted by Signorini and Volpato ${ }^{28}$, the deficit in the action fluency test was also independent from the duration of the disease.
No effect of gender was observed on the performance of any of the verbal fluency tests and these results are consistent with the literature ${ }^{27,29}$. Additionally, no age effect was observed in the different verbal fluency tests, which is coherent with data with reference to semantic fluency ${ }^{30}$, to action fluency ${ }^{28}$, and phonemic fluency ${ }^{30}$. Although no significant impact of age was observed, the results obtained in the Spearman correlation analysis showed a non-significant trend for the performance to decrease as age increases.

In the studied sample, our results showed that: a) the action verbal fluency test was the only task that showed different results in patients and controls; b) for traditional tests of verbal fluency, there were no significant differences between PD and control subjects; c) the difference between the production of verbs and nouns may be understood as a linguistic deficit specific for verbs in PD patients without dementia, whose frontal functions are thought to be affected; d) the specific deficit of verb evocation detected appears before the patients show clear signs of cognitive impairment; e) academic education was the only biographical variable with significant influence on the results of the different tests, and no gender or disease evolution time effect was detected in the test performance.

The results of this study emphasise the idea that the action verbal fluency test can be useful as a supplementary indicator for the assessment of executive functions. Future researches in a larger sample and additional tests of executive functions are required.

\section{References}

1. Vigliocco G, Vinson DP, Druks J, Barber H, Cappa SF. Nouns and verbs in the brain: a review of behavioural, electrophysiological, neuropsychological and imaging studies. Neurosci Biobehav Rev. 2011;35(3):407-26.http://dx.doi.org/10.1016/j.neubiorev.2010.04.007

2. Piatt AL, Fields JA, Paolo AM, Tröster Al. Action (verb naming) fluency as an executive function measure: convergent and divergent evidence of validity. Neuropsychologia. 1999;37(13):1499-503. http://dx.doi.org/10.1016/S0028-3932(99)00066-4

3. Damasio AR, Tranel, D. Nouns and verbs are retrieved with differently distributed neural systems. Proc Natl Acad Sci USA. 1993;90(11):4957-60. http://dx.doi.org/10.1073/pnas.90.11.4957

4. Rhee J, Antiquena P, Grossman M. Verb comprehension in frontotemporal degeneration: the role of grammatical, semantic and executive components. Neurocase. 2001;7(2):173-84. http://dx.doi.org/10.1093/neucas/7.2.173

5. Piatt AL, Fields JA, Paolo AM, Koller WC, Tröster Al. Lexical, semantic, and action verbal fluency in Parkinson's disease with and without dementia.J Clin Exp Neuropsychol. 1999;21(4):435-43. http://dx.doi.org/10.1076/jcen.21.4.435.885

6. Woods SP, Carey CL, Tröster Al, Grant I. Action (verb) generation in HIV-1 infection. Neuropsychologia. 2005;43(8):1144-51. http://dx.doi.org/10.1016/j.neuropsychologia.2004.11.018

7. Piatt AL, Fields JA, Paolo AM, Tröster Al. Action verbal fluency normative data for the elderly. Brain Lang. 2004;89(3):580-3. http://dx.doi.org/10.1016/j.bandl.2004.02.003

8. Woods SP, Scott JC, Sires DA, Grant I, Heaton RK, Tröster Al. Action (verb) fluency: test-retest reliability, normative standards, and construct validity. J Int Neuropsychol Soc. 2005;11(4):408-15. http://dx.doi.org/10.1017/S1355617705050460

9. Schrag A, Barone P, Brown RG, Leentjens AF, McDonald WM, Starkstein $S$ et al. Depression rating scales in Parkinson's disease: critique and recommendations. Mov Disord. 2007;22(8):1077-92. http://dx.doi.org/10.1002/mds.21333

10. Martins IP, Vieira R, Loureiro C, Santos ME. Speech rate and fluency in children and adolescents. Child Neuropsychol. 2007;13(4):319-32. http://dx.doi.org/10.1080/09297040600837370

11. Péran P, Rascol O, Démonet JF, Celsis P, Nespoulous JL, Dubois $B$ et al. Deficit of verb generation in nondemented patients with Parkinson's disease. Mov Disord. 2003;18(2):150-6. http://dx.doi.org/10.1002/mds.10306

12. Grossman M, Koenig P, DeVita C, et al. Neural representation of verb meaning: an fMRI study. Hum Brain Mapp. 2002;15(2):124-34. http://dx.doi.org/10.1002/hbm.10117

13. Tyler LK, Moss HE, Durrant-Peatfield MR, Levy JP. Conceptual structure and the structure of concepts: a distributed account of category-specific deficits. Brain Lang. 2000;75(2):195-231. http://dx.doi.org/10.1006/brln.2000.2353

14. Shapiro KA, Mottaghy FM, Schiller NO, Poeppel TD, Flüss MO, Müller HW et al. Dissociating neural correlates for nouns and verbs. Neuroimage. 2005;24(4):1058-67. http://dx.doi.org/10.1016/j.neuroimage.2004.10.015

15. Moro A, Tettamanti M, Perani D, Donati C, Cappa SF, Fazio F. Syntax and the brain: disentangling grammar by selective anomalies. Neuroimage. 2001;13(1):110-8. http://dx.doi.org/10.1006/nimg.2000.0668 
16. Cappelletti M, Fregni F, Shapiro K, Pascual-Leone A, Caramazza A. Processing nouns and verbs in the left frontal cortex: a transcranial magnetic stimulation study. J Cogn Neurosci. 2008;20(4):707-20. http://dx.doi.org/10.1162/jocn.2008.20045

17. Östberg P, Fernaeus SE, Hellström K, Bogdanović N, Wahlund LO. Impaired verb fluency: a sign of mild cognitive impairment. Brain Lang. 2005;95(2):273-9. http://dx.doi.org/10.1016/j.bandl.2005.01.010

18. Hughes DL, Bryan J. Adult age differences in strategy use during verbal fluency performance. J Clin Exp Neuropsychol. 2002;24(5):642-54. http://dx.doi.org/10.1076/jcen.24.5.642.1002

19. Fernaeus SE, Ostberg P, Hellström A, Wahlund LO. Cut the coda: early fluency intervals predict diagnoses. Cortex. 2008;44(2):161-9. http://dx.doi.org/10.1016/j.cortex.2006.04.002

20. Obonsawin MC, Crawford JR, Page J, Chalmers P, Cochrane R, Low G. Performance on tests of frontal lobe function reflect general intellectual ability. Neuropsychologia. 2002;40(7):970-7. http://dx.doi.org/10.1016/S0028-3932(01)00171-3

21. Parker DM, Crawford JR. Assessment of frontal lobe function: a handbook of neuropsychological assessment. London: Erlbaum; 1992.

22. Jurado MA, Mataro M, Verger K, Bartumeus F, Junque C. Phonemic and semantic fluencies in traumatic brain injury patients with focal frontal lesions. Brain Inj. 2000;14(9):789-95. http://dx.doi.org/10.1080/026990500421903

23. Liljeström M, Tarkiainen A, Parviainen T, Kujala J, Numminen J, Hiltunen J et al. Perceiving and naming actions and objects. Neuroimage. 2008;41(3):1132-41. http://dx.doi.org/10.1016/j.neuroimage.2008.03.016
24. d'Honincthun P, Pillon A. Verb comprehension and naming in frontotemporal degeneration: the role of the static depiction of actions. Cortex. 2008;44(7):834-47. http://dx.doi.org/10.1016/j.cortex.2007.04.003

25. Scholtissen B, Dijkstra J, Reithler J, Leentjens AF. Verbal fluency in Parkinson's disease: results of a 2-min fluency test. Acta Neuropsychiatr. 2006;18(1):38-41. http://dx.doi.org/10.1111/j.0924-2708.2006.00122.x

26. Boulenger V, Roy AC, Paulignan Y, Deprez V, Jeannerod M, Nazir TA. Cross-talk between language processes and overt motor behavior in the first $200 \mathrm{msec}$ of processing. J. Cogn. Neurosci. 2006;18(10):1607-15. http://dx.doi.org/10.1162/jocn.2006.18.10.1607

27. Zarino B, Crespi M, Launi M, Casarotti A. A new standardization of semantic verbal fluency test. Neurol Sci. 2014;35(9):1405-11. http://dx.doi.org/10.1007/s10072-014-1729-1

28. Signorini M, Volpato C. Action fluency in Parkinson's disease: a follow-up study. Mov Disord. 2006;21(4):467-72. http://dx.doi. org/10.1002/mds.20718

29. Mack WJ, Teng E, Zheng L, Paz S, Chui H, Varma R. Category fluency in a latino sample: associations with age, education, gender, and language. J Clin Exp Neuropsychol. 2005;27(5):591-8. http://dx.doi.org/10.1080/13803390490918417

30. Henry JD, Phillips, LH. Covariates of production and perseveration on tests of phonemic, semantic and alternating fluency in normal aging. Neuropsychology, development, and cognition. Neuropsychol Dev Cogn B Aging Neuropsychol Cogn. 2006;13(3-4):529-51. http://dx.doi.org/10.1080/138255890969537 